\title{
A interação entre movimentos sociais e sistema estatal no Brasil: um debate a partir das contribuições de Claus Offe e Nicos Poulantzas*
}

Thiago Aparecido Trindade** Caio Martins Bugiato***

Resumo: O objetivo central deste texto consiste em analisar a relação entre movimentos sociais e Estado a partir de um diálogo com a literatura brasileira recente. Nos últimos anos, estudiosos dedicaram-se a pensar a luta pela democracia a partir da inserção dos ativistas no interior das instituições. O problema é que esse debate relegou a segundo plano questões sobre o Estado fundamentais para uma compreensão mais abrangente dos limites da luta institucional. Para suprir tal lacuna, nossa proposta coloca em diálogo o recente debate brasileiro sobre a interação entre movimentos sociais e Estado com a discussão teórica neomarxista, conferindo centralidade aos elementos da dinâmica estatal que relativizam a influência exercida pelos ativistas no interior do Estado. Em síntese, para que a luta "por dentro" das instituições tenha maior eficácia, ela precisa necessariamente estar ancorada por uma forte capacidade de mobilização do lado "de fora".

Palavras-chave: Movimentos sociais. Sistema estatal. Democracia. Agenda relacional. Neomarxismo.

\section{The interaction between social movements and state system in Brazil: a debate from the contributions of Claus Offe and Nicos Poulantzas}

Abstract: The central goal of this article is to analyze the relationship between social movements and the State system dialoguing with the recent Brazilian literature. Lately, many researchers in Brazil have dedicated themselves to conceive the struggle for democracy from the insertion of activists within the institutions. The problem is that this debate has relegated to the background several issues on the State, which are fundamental for a more appropriated conception about the limits of the institutional mobilization. To fill this gap, our proposition puts in dialogue the recent Brazilian debate on the interaction between social movements and State with the neomarxist theoretical discussion, putting emphasis in specific elements of the State dynamics that operate in order to relativize the influence that the activists could exert within the institutions. In short, for the "inside" struggle of institutions to be more effective, it must necessarily be anchored by a strong mobilization "outside".

Keywords: Social movements. State system. Democracy. Relational agenda. Neomarxism.

\author{
* Este artigo é \\ produto da pesquisa \\ intitulada "Interações \\ socioestatais e \\ processos de \\ institucionalização \\ no nível federal: um \\ balanço pós-2016", \\ financiada pelo CNPq \\ (Chamada MCTIC/ \\ CNPq № 28/2018 \\ - Universal/Faixa \\ A). Agradecemos \\ à leitura atenta \\ e rigorosa dos \\ pareceristas \\ anônimos da Revista \\ Sociedade e Estado, \\ que contribuiu de \\ forma relevante para \\ a melhoria do texto. \\ ** Thiago Aparecido \\ Trindade é doutor em \\ ciências sociais pelo \\ Instituto de Filosofia \\ e Ciências Humanas \\ da Universidade \\ Estadual de \\ Campinas (IFCH/ \\ Unicamp), professor \\ adjunto do Instituto \\ de Ciência Política \\ da Universidade \\ de Brasília (UnB), \\ Brasília, DF, Brasil. \\ Vinculado ao \\ Grupo de Pesquisa \\ sobre Democracia \\ e Desigualdades \\ (Demodê), onde \\ coordena a linha \\ de pesquisa \\ "Democracia e \\ ativismo político". \\ É tutor bolsista \\ do Programa de \\ Educação Tutorial \\ em Ciência Política
}


da UnB, financiado pelo Ministério da Educação. Orcid: 0000-0001 8983-5255. <th.trindade83@ gmail.com>.

*** Caio Martins Bugiato é doutor em ciência política pelo Instituto de Filosofia e Ciências Humanas da Universidade Estadual de Campinas (IFCH/ Unicamp). Professo de Ciência Política e Relações Internacionais da Universidade Federal Rural do Rio de Janeiro (UFRRJ), Rio de Janeiro, Brasil. Orcid: 0000-00029378-4830. <bugiato@gmail. com>.

\section{Introdução}

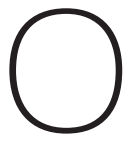

debate teórico sobre a relação entre Estado e movimentos sociais no Brasil contemporâneo é amplamente pautado pela necessidade em desconstruir as concepções dicotômicas arquitetadas entre o final dos anos 1970 e meados dos anos 1990. Forjadas no período mais intenso da luta pela redemocratização do país, tais concepções concebiam movimentos sociais e Estado como esferas separadas, cuja relação era pautada essencialmente pelo conflito e pela externalidade. Ou seja, era um debate profundamente associado ao fato de o Estado autoritário oferecer pouca ou nenhuma permeabilidade aos movimentos populares engajados na luta pela democracia, inibindo abordagens focadas nas eventuais interações institucionais entre os dois campos.

Todavia, o retorno ao regime democrático, na segunda metade da década de 1980, além de restabelecer o direito de voto, ampliou as possibilidades de inserção institucional para vários movimentos sociais e organizações civis, sobretudo em razão da criação e/ou difusão de um número considerável de Instituições Participativas (Avritzer, 2008) - com destaque para os conselhos gestores de políticas públicas e os Orçamentos Participativos (OPs). Nesse contexto, as formulações teóricas predominantes na literatura já não davam conta de explicar a nova configuração das relações entre Estado e sociedade, o que fez os termos do debate sofrerem modificações relevantes no decorrer da década de 1990. A imbricação entre atores estatais e civis, concebida anteriormente como algo que deveria ser evitado sob o risco de "cooptação" (Feltran, 2005; 2007), torna-se alvo de atenção privilegiada na agenda de pesquisa emergente e deixaria de ser considerada (ao menos pelos autores de maior centralidade no debate) como algo negativo. Nas palavras de Luciana Tatagiba:

\footnotetext{
Nos novos estudos, o mais interessante é perceber como a própria relação entre sociedade civil e sociedade política se constitui como questão empírica e teórica a ser enfrentada (Tatagiba, 2011: 236, grifo no original).
}

Nesse sentido, essa nova agenda, aqui denominada "agenda (ou abordagem) relacional" (Silva, 2006: 160), chamou atenção para a dimensão colaborativa (e não apenas confrontante) da relação que se estabelece entre atores estatais e civis, enfatizando que a presença dos movimentos e ativistas sociais dentro do sistema estatal, bem como sua capacidade de influenciar decisões relacionadas às políticas públicas, é muito maior do que as formulações teóricas tradicionais sobre os movimentos sociais supõe (Gurza Lavalle \& Szwako, 2015; Carlos, 2014; 2015). A 
literatura brasileira tem se destacado internacionalmente ao intensificar os estudos empíricos sobre as redes de ativistas que cruzam as fronteiras entre Estado e sociedade civil (Abers \& von Bülow, 2011), desvelando um amplo repertório de interação conflitivo e colaborativo (com ênfase no último) que estrutura a relação entre os movimentos sociais e o sistema estatal no Brasil (Abers, Serafim \& Tatagiba, 2014). A agenda relacional destacou a heterogeneidade constitutiva tanto da sociedade civil como da sociedade política, concentrando-se em identificar e compreender as diferentes possibilidades de interação institucional entre atores civis e estatais (Dagnino, Olvera \& Panfichi, 2006; Silva, 2006). Tal postura analítica permitiu a problematização de concepções que tradicionalmente conceberam os movimentos sociais como outsiders em relação ao sistema estatal, ou seja, como atores que estão necessariamente situados do lado de fora das instituições e ocupam "naturalmente" a posição de desafiantes das autoridades.

É justamente neste ponto que entendemos ser necessário problematizar o debate em curso. Se por um lado é verdade que a agenda relacional teve o mérito de romper as concepções dicotômicas do passado, por outro ela tem realçado os vínculos institucionais (especialmente colaborativos) entre movimentos sociais e Estado, sem contudo problematizar a fundo os termos nos quais se dá essa interação institucional. Nesse aspecto, o principal problema da abordagem relacional é sua consideração de que a heterogeneidade do Estado e a consequente permeabilidade das instituições públicas forja um cenário no qual o Estado está "em disputa": de fato, essa disputa existe, mas suas condições são muito mais assimétricas do que essa agenda de pesquisa parece disposta a admitir. Ao que parece, o contexto recente de maior abertura do Estado brasileiro entre os anos de 2003 a 2014 ${ }^{1}$, sobretudo em decorrência do ciclo petista na administração federal, fez com que muitos estudiosos relegassem a segundo plano questões estruturais relacionadas ao funcionamento do Estado e à forma com que este responde às demandas sociais.

Nesse sentido, o presente artigo se propõe a realizar um debate teórico com o intuito de oferecer um contraponto à abordagem relacional, enfatizando aspectos associados à dinâmica de funcionamento do aparelho estatal na sociedade capitalista que, a nosso ver, são fundamentais para a compreensão da interação entre Estado e movimentos sociais mais próxima da realidade. Mais especificamente, pretendemos apontar que a presença física de ativistas sociais no interior das instituições não equivale necessariamente a uma capacidade decisiva em influenciar os rumos do sistema estatal.

Do ponto de vista metodológico, colocamos em diálogo os estudos associados à agenda relacional no Brasil com a literatura denominada neomarxista, mais es-

1. Consideramos que o período de maior abertura do Estado brasileiro à inserção institucional de diversos movimentos sociais se deu entre os anos de 2003 a 2014. Entendemos que no segundo mandato de Dilma Rousseff, iniciado em 2015, embora o governo federal ainda fosse comandado pelo $\mathrm{PT}$, já não estávamos mais em um momento de abertura, mas sim de fechamento do regime. 
2. Cabe enfatizar que não é nossa intenção realizar uma ampla revisão da literatura neomarxista, dando conta das ideias e proposições de todos/as os/as autores/as que, em tese, integram essa corrente, como Adam Przeworski, Bob Jessop, Goran Therborn, Ellen Wood, Perry Anderson, dentre outros/as. Isso seria, por si só, objeto de outro artigo. A proposta de focar a discussão em Poulantzas e Offe é, acima de tudo, uma opção analítica, tendo em vista a necessidade de um recorte mais objetivo para o desenvolvimento de nosso argumento.

3. Para maior conhecimento sobre as limitações analíticas do neomarxismo, bem como seus contrapontos com outras abordagens (em especial o neoinstitucionalismo), ver Marques (1997) e Rocha (2005). pecificamente a partir das contribuições de dois de seus autores mais relevantes, a saber, Claus Offe e Nicos Poulantzas². O intuito básico consiste em demonstrar principalmente que a atuação do Estado, independentemente de quem ocupe o governo, tem um sentido estruturalmente direcionado na sociedade capitalista. neomarxismo, segundo Eduardo Marques, é "a corrente de estudos que voltou a trabalhar o papel do Estado na sociedade capitalista no interior do paradigma marxista a partir da década de 60", constituindo-se em uma perspectiva analítica que "apresenta grande valor explicativo das ações do Estado" (Marques, 1997: 68).

Ao considerar o atual contexto político, no qual vários espaços de participação institucional na esfera federal estão sendo profundamente enfraquecidos ou até mesmo extintos, nos parece necessário refletir com mais atenção sobre a emergência da abordagem relacional e seus pressupostos. A ruptura institucional experimentada pela democracia brasileira no ano de 2016 e o retrocesso democrático em marcha colocaram em xeque muitas das expectativas e apostas que se fizeram ao longo dos últimos 30 anos pela esquerda hegemônica no Brasil, notadamente no que se refere às possibilidades de transformação social pela via da luta institucional. Como lembrado por Debora Almeida,

havia uma aposta muito grande de que a inclusão de grupos tradicionalmente marginalizados na política poderia contrabalançar o controle da elite sobre o Estado e democratizá-lo (Almeida, 2017: 654).

Torna-se necessário discutir, portanto, por quais razões tais expectativas não se confirmaram satisfatoriamente, e é justamente nesse ponto que vislumbramos a possibilidade de um diálogo crítico com a agenda relacional a partir das contribuições de Offe e Poulantzas.

A análise neomarxista, claro, não é isenta de problemas. O principal ponto a ser criticado consiste no fato de que ela é pouco aberta ao caráter contingente da luta política, na medida em que confere ênfase quase que determinística ao poder econômico no processo político, o que significa, no limite, que os resultados da luta social estarão basicamente pré-determinados (Marques, 1997: 90). Este é um debate, contudo, que não tem condições de ser travado aqui ${ }^{3}$. Cientes das limitações inerentes ao neomarxismo, nosso intuito neste texto consiste em iluminar determinados aspectos que o debate recente no Brasil sobre a interação entre movimentos sociais e Estado relegou a segundo plano. Ademais, os problemas do neomarxismo não anulam o fato de que tal abordagem está em larga medida correta ao privilegiar o capital enquanto ator fundamental "na constituição das ações 
do Estado", uma vez que, de fato, os capitalistas "ocupam um lugar privilegiado de poder em relação a todos os demais atores na sociedade" (Marques, 1997: 90).

Portanto, nosso objetivo será o de demonstrar que mesmo se estabelecidos inúmeros pontos de interseç̧ão entre atores estatais e civis; ainda que muitos espaços de participação institucional sejam abertos; e que ativistas ocupem postos relativamente importantes na burocracia pública, estes vínculos se organizam de modo profundamente assimétrico, o que sugere que a capacidade dos movimentos sociais em influenciar as políticas públicas (e a ação estatal em um sentido mais amplo) depende essencialmente de seu poder de mobilização e disrupção, pressionando a máquina estatal desde fora (Maricato, 2014; Miguel, 2017).

O texto divide-se em três partes, além desta introdução. Na primeira, discutimos a emergência da agenda relacional no Brasil a partir da crítica às teorias consolidadas sobre os movimentos sociais e à perspectiva dicotômica, destacando que o debate teórico foi gradualmente se alinhando à estratégia da esquerda hegemônica no país de luta por dentro do Estado. Na segunda parte, trazemos as contribuições de Claus Offe e Nicos Poulantzas para oferecer um entendimento mais aprofundado sobre a dinâmica do Estado na sociedade capitalista. No terceiro tópico, buscamos confrontar os pressupostos centrais da agenda relacional no Brasil às análises de Poulantzas e Offe sobre o Estado. Por fim, apresentamos nossas considerações finais sobre as questões debatidas no artigo, buscando apresentar alguns pontos que podem contribuir para o avanço do debate aqui exposto. Ressalte-se que nosso intuito não é, de modo algum, colocar em questão a relevância dos estudos trazidos pela abordagem relacional e os inúmeros ganhos analíticos daí decorrentes, mas simplesmente contribuir para o enriquecimento do debate teórico.

Em tempo, três informações relevantes. Primeiro, a definição de Estado/sistema estatal com a qual trabalhamos é aquela proposta por Miliband, para quem o

Estado significa um número de determinadas instituições que em seu conjunto constituem a sua realidade e que interagem como partes daquilo que pode ser denominado o sistema estatal (Miliband, 1972: 67).

Tal sistema, no caso brasileiro, é composto essencialmente pelo governo federal, Congresso Nacional, Poder Judiciário, Ministério Público, pelas assembleias legislativas, pelos governos locais (estaduais, municipais e distrital), pelas Forças Armadas, corporações públicas (Banco do Brasil, Petrobrás etc.) e pela administração pública em geral. Segundo, é necessário pontuar que o texto não pretende (nem mesmo 
4. Para uma análise aprofundada sobre a obra dos referidos autores (bem como de outros), ver Martin Carnoy (1994).

5. Texto originalmente publicado como artigo em 2014 na revista Novos Estudos (n. 98), com o título "Mecanismos de exclusão política e os limites da democracia liberal: uma conversa com Poulantzas, Offe e Bourdieu". tem condições para tanto) desenvolver a fundo as ideias de Offe e Poulantzas ${ }^{4}$, mas sim destacar elementos centrais no pensamento destes dois autores que colaboram para a construção do argumento central do artigo.

Por último, cabe pontuar que o presente texto procura avançar em uma agenda recentemente proposta por Luís Felipe Miguel $(2018)^{5}$, quando o autor colocou em diálogo as perspectivas teóricas de Nicos Poulantzas, Claus Offe e Pierre Bourdieu para pensar os limites da luta política por dentro do Estado. Segundo o autor, esse é um debate particularmente importante a ser travado no Brasil, país no qual "a combinação entre a experimentação democrática posterior à Constituição de 1988 e a chegada ao governo do Partido dos Trabalhadores (PT), em 2003", direcionou o foco da luta política e "das esperanças de transformação social para o interior do aparelho de Estado" (Miguel, 2018: 64). A ideia do presente artigo surgiu, portanto, a partir da provocação feita pelo referido autor.

\section{Crítica à perspectiva dicotômica: o debate teórico sobre movimentos sociais e a emergência da "agenda relacional" no Brasil}

A década de 1980 foi um período de ampla agitação política e social no Brasil, sobretudo em decorrência das grandes mobilizações populares pela redemocratização. Ao menos desde o final dos anos 1970, assistia-se à emergência na cena pública de inúmeros movimentos sociais urbanos (Jacobi, 1987; Caldeira \& Holston, 2004) que, conjugados com a retomada das mobilizações no meio sindical (Bava, 1994), conformaram um campo de atuação política em prol da democracia que seria interpretado como uma "novidade" por muitos pesquisadores (Sader, 1988; Doimo, 1995; Paoli, 1995). A novidade deste cenário residia especialmente na forma de organização dos sujeitos políticos emergentes: seu discurso de autonomia em relação ao sistema estatal e suas práticas de caráter espontâneo e horizontal anunciavam uma espécie de reconfiguração dos padrões de ação coletiva em uma sociedade profundamente marcada pelo autoritarismo de Estado e pelo clientelismo.

Naquele contexto, munida por noções como "autonomia", "espontaneidade" e "ação direta", a agenda de pesquisa sobre os movimentos sociais apresentou um enquadramento teórico no qual os ativistas mantinham necessariamente posição de externalidade para com o sistema estatal, uma vez que integravam

organizações que se caracterizavam efetivamente como outsiders em relação à política instituída e que tinham na ação contestató- 
ria uma das poucas possibilidades de expressão política (Silva \& Oliveira, 2011: 89).

A concepção de movimento social enquanto outsider em relação ao sistema estatal provém das teorias mais consolidadas sobre estes atores, que, a rigor, podem ser separadas em duas grandes escolas, a saber, a estadunidense e a europeia, cada uma enfatizando aspectos diferentes da ação coletiva. Enquanto a vertente estadunidense foca na dimensão mais estratégica e instrumental da ação - baseando seu enfoque no modelo do ator racional -, os europeus partem de uma perspectiva declaradamente normativa e mais centrada na construção da identidade coletiva, na autonomia dos movimentos frente ao Estado e no caráter espontâneo e horizontal dessa forma de mobilização - sem, contudo, negar inteiramente sua dimensão estratégica (Tatagiba, 2008; Alonso, 2009; Buechler, 2016).

A despeito das diferenças entre as duas vertentes, é possível identificar um traço comum, que acabou por estabelecer um entendimento relativamente consensual na literatura internacional sobre os movimentos sociais: trata-se de uma forma de ação coletiva de caráter predominantemente extrainstitucional. Para os europeus corrente denominada por Teoria dos Novos Movimentos Sociais -, os movimentos eram interpretados a partir de sua postura frente às instituições políticas, pelas características de suas demandas e pelo seu formato organizacional. Os "novos" movimentos teriam traços peculiares em relação aos "velhos": estes buscavam disputar o poder no Estado, apresentavam demandas centradas nas questões materiais/econômicas e se organizavam sobretudo através de partidos e sindicatos, organizações rigidamente hierarquizadas. Por seu turno, os novos movimentos se mantinham autônomos frente ao sistema estatal, preocupavam-se muito mais em disputar os valores culturais na sociedade, focavam suas lutas nas demandas pós-materiais (pacifismo, antirracismo, feminismo, ambientalismo, dentre outras), e se organizavam em formatos predominantemente horizontalizados. Uma das características que mais se sobressaiu nessa análise certamente foi a distância que estes novos movimentos procuravam manter em relação às instituições políticas, valorizando sua autonomia frente ao Estado e às autoridades públicas.

Já a vertente estadunidense trabalhava com uma perspectiva diferente, sendo que essa separação entre movimento social e Estado era compreendida de outra forma. Na realidade, para os analistas da Teoria do Processo Político, movimento e Estado eram atores que estavam em constante interação, mas sempre na chave do conflito (Tatagiba 2008). Não por acaso, o conceito de repertório formulado por Charles Tilly (1995; 2010), um dos principais expoentes dessa escola, se refere basicamente a um conjunto de formas de ação, em uma referência aos diferentes 
modos através dos quais as pessoas se manifestam coletivamente e encaminham suas demandas ao Estado. Na concepção desta corrente, os movimentos sociais são compreendidos sobretudo como atores desafiantes, que estão situados fora do sistema estatal e que agem de forma conflitiva justamente com o intuito de atrair a atenção dos oponentes e chamar a atenção para suas demandas (Tarrow, 2011: 10). Em suma, o Estado acaba sendo muitas vezes enquadrado como "um inimigo, frente ao qual os movimentos sociais ou a sociedade civil têm que medir forças" (Abers \& von Bülow, 2011: 54).

Logo, tanto pela ótica da escola europeia como de sua contraface estadunidense, os movimentos sociais são atores que não estão situados dentro do Estado. São, portanto, concebidos como outsiders em relação às instituições, cuja ação inevitavelmente assumirá um caráter primordialmente extrainstitucional. A formulação conceitual de James Jasper parece bastante adequada para sintetizar esses elementos:

\footnotetext{
os movimentos sociais são esforços persistentes e intencionais para promover ou obstruir mudanças jurídicas e sociais de longo alcance, basicamente fora dos canais institucionais normais sancionados pelas autoridades (Jasper, 2016: 23, grifo nosso).
}

No caso brasileiro em particular, é amplamente reconhecido pela literatura que a linha europeia de pensamento foi em larga medida hegemônica na interpretação dos movimentos sociais no período de transição política entre fins de década de 1970 e início dos anos 1990 (Jacobi, 1987; Gohn, 2010; Gurza Lavalle, 2003; Alonso, 2009). Afinal, o caráter normativo da Teoria dos Novos Movimentos Sociais e sua preocupação com a transformação social se encaixava muito melhor no contexto de luta contra o Estado autoritário e pela democracia no Brasil em comparação com as teorias estadunidenses.

Todavia, foi se tornando cada vez mais evidente que as interpretações dos pesquisadores brasileiros naquele momento específico acabaram sendo distorcidas em razão do contexto político. A luta contra o regime autoritário - quando o Estado era "o único" inimigo a ser combatido - contribuiu para uma leitura na qual a relação entre movimentos sociais e Estado era concebida basicamente pela ótica do conflito e da externalidade, produzindo, segundo análise feita à época por Pedro Jacobi (1987: 12), uma "interpretação polarizada que escamoteia o fato de ambos os polos integrarem-se no processo". Gradualmente, portanto, o caso brasileiro passou a oferecer pistas que ampliaram a percepção de que havia certa dissonância entre a interpretação acadêmica e a realidade empírica. Conforme Ruth Correia Cardoso: 
[...] em nome de uma ciência social crítica, nós fizemos uma ciência social engajada e pouco crítica, utilizando os discursos que os próprios movimentos sociais realizavam e ofereciam, estando as interpretações muitas vezes coladas a esses discursos. [...] Quando se tratava o espontaneísmo do movimento, por exemplo, não se via o resto. [...] Certas coisas foram deixadas um pouco de lado, não porque os pesquisadores não soubessem, mas, na verdade, porque as interpretações ficaram bastante coladas ao discurso dos movimentos (Cardoso, 1994: 84-85).

Nesse sentido, muito influenciados pelas lentes analíticas da Teoria dos Novos Movimentos Sociais, boa parte dos analistas tomou o discurso das lideranças populares como sendo a própria realidade, quando, em verdade, este discurso era apenas um aspecto da realidade. Inevitavelmente, isso gerou distorções importantes no que se refere ao debate sobre as formas de interação entre movimentos sociais e sistema estatal.

Entretanto, recorrendo à análise de Vera Telles, Marcelo Silva e Gerson Oliveira apontam que "a ideia da 'sociedade contra o Estado' não deve ser criticada apenas como simplismo ou ilusão de ótica" (Telles, apud Silva \& Oliveira 2011: 89), afinal, em uma sociedade na qual "a violência e a exclusão política apareciam como fatores determinantes", diante da figura opressora do Estado "a sociedade aparecia como alternativa política, como lugar no qual o desejo de liberdade poderia alimentar-se e traduzir-se numa ação possível" (Telles, 1988: 280, apud Silva \& Oliveira, 2011: 89-90). Ou seja, a despeito das necessárias críticas, aquela agenda de pesquisa não estava totalmente desvinculada da realidade.

No entendimento de Silva e Oliveira, porém, o problema central é que as interpretações daquele contexto específico cristalizaram determinadas percepções, universalizando a ideia de que os movimentos sociais são naturalmente outsiders em relação ao sistema estatal e que a interação entre as duas esferas se dá essencialmente na perspectiva do confronto, jamais da colaboração; dessa forma, conformou-se um modelo teórico-normativo no qual os "verdadeiros" movimentos sociais seriam sempre combativos e autônomos em relação ao Estado (Silva \& Oliveira, 2011: 90).

Com isso, a aproximação entre o campo movimentalista e os atores estatais processo que já vinha se delineando desde o início da década de 1980 (Cardoso, 1994; Jacobi, 1987; Kowarick, 1987) - foi praticamente ignorado pelos estudiosos naquele momento histórico. Conforme destacado por Adrian Gurza Lavalle (2003) e Gabriel Feltran (2005), quando este fenômeno se tornou evidente de tal modo que não era mais possível ignorá-lo, muitos analistas foram categóricos em afirmar 
que essa aproximação entre ativistas e Estado significava refluxo, desmobilização e cooptação. Dessa forma, a agenda de pesquisa sobre movimentos sociais teria se descolado, em alguma medida, da própria realidade, uma vez que ela estava pouco instrumentalizada para analisar as complexas interações que se estabelecem entre os atores civis e o mundo sistêmico (Silva, 2015). Na medida em que os eventos da realidade não se encaixavam nos modelos analíticos tradicionais, que tinham como suposto básico a condição de outsiders dos movimentos sociais em relação ao sistema estatal, o resultado foi um "imobilismo teórico" (Doimo, 1995) que trouxe grandes dificuldades para o avanço do debate.

Um fator adicional tornou essa interpretação dicotômica ainda mais problemática: a fundação do Partido dos Trabalhadores (PT) - datada de 1980 - e sua relevante inserção no jogo eleitoral com a gradual transição ao regime democrático. O PT nasceu como partido de massas, responsável por representar e aglutinar os trabalhadores e vários setores tradicionalmente excluídos da política brasileira na construção de uma nova plataforma política, centrada em questões como participação popular, reforma agrária e distribuição mais justa da riqueza social (Feltran, 2006). Nos anos subsequentes, figuras relevantes do partido conquistam cargos no legislativo através do processo eleitoral. Nas eleições municipais de 1988, o PT passou a comandar prefeituras em centros urbanos de grande relevância nacional, como Porto Alegre (RS) e São Paulo (SP) (Dagnino, 2002). Nesse processo, diversos ativistas também se tornaram militantes do partido e construíram sua trajetória de modo que a militância no movimento e no PT se confundiam (Doimo, 1995; Mische, 2008; Tatagiba \& Teixeira, 2016).

Ademais, pelo menos desde a segunda metade dos anos 1980 - especialmente após a promulgação da Constituição de 1988) - já era possível detectar um processo de maior abertura do Estado brasileiro para com os atores civis, o que se deveu em grande medida à criação e difusão de inúmeras Instituições Participativas nas diferentes escalas de governo. Tal processo criou inúmeros pontos de intersecção entre a sociedade civil e o Estado que derivavam, em grande parte, das próprias reivindicações dos setores populares por maior democratização dos processos decisórios e por mais eficácia nas políticas públicas (Tatagiba, 2002: 47), promovendo um verdadeiro processo de institucionalização da participação social (Gurza Lavalle, 2011; Gurza Lavalle \& Isunza Vera, 2011).

Posteriormente, com a vitória eleitoral do PT nas eleições presidenciais de 2002, tanto a inserção de ativistas sociais na burocracia estatal como a participação institucionalizada se ampliaram consideravelmente. Além da criação de inúmeros ministérios e de vários conselhos gestores na esfera federal nas mais diversas áreas de 
políticas públicas, a realização de conferências temáticas em escala nacional também se rotinizou (Abers, Serafim \& Tatagiba, 2014; Avritzer, 2016). A associação, portanto, entre o processo de democratização do Estado brasileiro com a ascensão do PT à Presidência da República, em 2003, reconfigurou de forma significativa as oportunidades de inserção institucional para muitos ativistas sociais. Nesse sentido, pelo menos desde a criação do PT, é possível identificar uma "opção" histórica do campo democrático-popular em priorizar a luta por dentro das instituições, como bem explicado por Feltran:

\begin{abstract}
O surgimento do PT [...] sinalizou para a possibilidade, até então impensável, de um partido de trabalhadores [...], por via eleitoral e oferecendo um conteúdo programático às reivindicações que surgiam na sociedade civil, mediar o trânsito até o Estado do projeto de transformação elaborado originalmente pelos setores populares. [...] O projeto "democrático popular" é marcado [...] desde as suas origens, por uma aposta fundamental que se delinearia mais claramente ao longo dos anos de 1980: trata-se da aposta na possibilidade de migração das demandas e anseios dos movimentos sociais, que apareciam no final dos anos de 1970, para canais de participação ativa da sociedade civil na gestão e na definição do funcionamento do Estado. [...] este projeto apostou nas possibilidades de democratização conjunta do Estado e da sociedade pela articulação entre a via eleitoral e a implementação de canais de participação popular nos governos (Feltran, 2006: 373, grifo do autor).
\end{abstract}

Ora, o fato é que essa aposta histórica também reverberou fortemente no debate acadêmico, o que contribuiu decisivamente para redefinir os termos da agenda de pesquisa sobre a relação entre movimentos sociais e Estado no Brasil. Essa mudança nos rumos do debate foi registrada pelo importante texto de Gurza Lavalle (2003): uma nova agenda de pesquisa foi sendo pouco a pouco consolidada, agenda esta menos focada

nos atores e/ou sujeitos coletivos [e mais preocupada com] as dinâmicas de espaços e ambientes institucionais (orçamento participativo, conselhos), assim como seus efeitos sobre os atores e interesses da sociedade civil neles representados (Gurza Lavalle, 2003: 109).

Nessa nova agenda, as múltiplas formas de interação institucional entre movimentos sociais e Estado passam a ser encaradas como parte constitutiva do processo de luta pela democracia, e não como sinônimo de cooptação ou desmobilização (Dagnino, Olvera \& Panfichi, 2006; Tatagiba, 2011; Carlos, 2014; 2015; Abers, Serafim \& Tatagiba, 2014; Almeida, 2017). Fortemente alinhado a essa perspectiva 
é o trabalho de Rebeca Abers e Marisa von Bülow, que remete aos estudos sobre o feminismo latino-americano para argumentar que, nos anos 1990, lideranças importantes desse movimento "acabaram ocupando posições nas burocracias estatais", o que não necessariamente se traduz em "cooptação ou perda de autonomia" (Abers \& von Bülow, 2011: 66). Ao analisarem a interação entre as diferentes organizações sociais e o governo federal nos dois mandatos de Lula (2003-2010), Rebecca Abers, Lizandra Serafim e Luciana Tatagiba avançam na mesma direção, alegando que os ativistas que

assumiram cargos na burocracia federal frequentemente transformaram agências governamentais em espaços de militância nos quais continuaram a defender bandeiras desenvolvidas previamente no âmbito da sociedade civil (Abers, Serafim \& Tatagiba, 2014: 326).

Em texto posterior, Marcelo Silva (2015: 6) definiu as três principais formas de interação entre os ativistas sociais e o sistema estatal no Brasil pós-1988:

i. a edificação de uma relevante arquitetura de participação institucional;

ii. as oportunidades de participação que se abriram para os ativistas nos processos de implementação das políticas públicas; e

iii. a ocupação de cargos na burocracia governamental.

Estes fenômenos da realidade empírica contribuíram fortemente para redefinir os rumos da agenda de pesquisa sobre a relação entre movimentos sociais e sistema estatal no Brasil, consolidando a chamada agenda relacional.

Na perspectiva desta, os movimentos sociais deixam de ser compreendidos como atores necessariamente situados do "lado de fora" das instituições, ao mesmo tempo em que também se procura jogar luz na dimensão colaborativa - e não apenas confrontacional - da relação que se estabelece entre ativistas sociais e agentes estatais. Esse é, precisamente, um dos elementos fundamentais (senão o elemento fundamental) desse debate: como resposta às formulações dicotômicas do passado, mais especificamente do período que compreende os fins da década de 1970 até praticamente meados dos anos 1990, os pesquisadores que aderiram à abordagem relacional têm como um de seus principais objetivos analisar a interação entre movimentos sociais e sistema estatal para além da dimensão confrontacional, mapeando os diversos vínculos colaborativos que se estabelecem entre as duas esferas (Dagnino, Olvera \& Panfichi, 2006: 38). 
Em seu texto sobre os "repertórios de interação" entre a sociedade e o Estado no governo Lula, Abers, Serafim e Tatagiba explicitam de forma bastante evidente a mudança de tom no debate:

Adaptamos o conceito de repertório, originalmente concebido para o estudo dos movimentos sociais sob a chave das dinâmicas contenciosas, para relações que envolvem também dinâmicas colaborativas entre atores no Estado e na sociedade (Abers, Serafim \& Tatagiba, 2014: 327)

A análise cuidadosa dessa literatura recente demonstra claramente que o seu foco se deteve em formas de interação institucional entre os movimentos sociais e o Estado de caráter predominantemente colaborativas, o que constitui, de certo modo, um "acerto de contas" com o passado. Com efeito, o objetivo central da agenda relacional consistiu exatamente em demonstrar as limitações das duas grandes escolas de pensamento sobre movimentos sociais para explicar o caso brasileiro de forma adequada, destacando as múltiplas formas de interação nas quais agentes do Estado e ativistas sociais compartilham os mesmos espaços e atuam, em muitos contextos, de forma conjunta (Abers \& von Bülow, 2011).

Porém, para além das questões envolvidas no recorte da análise - se mais focada no confronto ou na colaboração -, é necessário chamar atenção para essa mesma literatura que já vinha identificando de forma sistemática, pelo menos desde o início dos anos 2000, uma série de dificuldades enfrentadas pelos ativistas nesse processo de aproximação com o meio político-institucional. Várias pesquisas têm detectado as frustrações de ativistas que se engajaram diretamente na atuação por dentro do Estado, sobretudo através da participação em espaços institucionais. Em estudo que se tornou referência importante para a área, Tatagiba destacou os questionamentos que vários militantes e pesquisadores vinham fazendo em relação aos ganhos advindos da atuação nesses espaços:

As dificuldades em conciliar ações de natureza estratégica e de trabalho junto às bases com ações concretas no processo de elaboração das políticas públicas, somadas a uma avaliação negativa quanto aos resultados práticos da participação institucional [...], têm levado muitos atores do campo progressista e democrático a repensarem a prioridade dada à dimensão institucional como forma privilegiada de luta política no decorrer dos anos 90 (Tatagiba, 2002: 99, grifo nosso).

Em estudo publicado oito anos depois, Ana Claudia Teixeira e Luciana Tatagiba (2010: 290-291) detectaram percepção semelhante ao entrevistarem ativistas en- 
gajados na participação institucional na cidade de São Paulo entre 2001 e 2004, durante a gestão Marta Suplicy. A lista de estudos com apontamentos similares em relação às frustrações dos ativistas, bem como sobre os limites da participação institucionalizada e, por conseguinte, das possibilidades de transformações mais incisivas pela via da ação institucional, é extensa (Silva, 2002; Almeida \& Tatagiba, 2012; Teixeira, 2013; Szwako, 2012; Blikstad, 2012; Tavares, 2012; Serafim, 2013; Pires, 2014; Romão, 2015; Avritzer, 2016; Trindade, 2018).

Frente ao atual contexto, faz-se necessário uma reflexão mais substantiva sobre esse conjunto de questões. As razões do retrocesso democrático em marcha são variadas e não encontram explicações simples, mas a reflexão teórica sobre o Estado é um exercício que oferece contribuições relevantes para o entendimento do atual momento histórico.

\section{O Estado na sociedade capitalista: as contribuições do neomarxismo}

O Estado brasileiro, a exemplo de muitos outros no mundo, é um Estado inserido em uma sociedade capitalista. Sem o intuito de simplificar discussão tão complexa, isso o torna - segundo a perspectiva marxista - um Estado capitalista, ou seja, sua atuação é estruturalmente orientada por condições específicas. Isso acontece não porque esse Estado seja um instrumento da classe dominante - no caso a burguesia -, mas porque a própria forma como a sociedade capitalista está estruturada impõe determinadas diretrizes a esse Estado e delimita seu campo de ação (Marx, 2006; Offe \& Ronge, 1984; Carnoy, 1994; Marques, 1997; 2016; Perissinotto \& Codato, 2010; Tavares, 2017; Miguel, 2018).

Para os fins do debate aqui exposto, é conveniente apresentar inicialmente a argumentação desenvolvida por Claus Offe. No campo das Teorias do Estado, o modelo teórico de Offe talvez seja uma das mais bem-sucedidas tentativas em explicar porque o Estado age da forma como age (Marques, 1997; Borchert \& Lessenich, 2016; Miguel, 2018), ou seja, protegendo os interesses dos grandes empresários e viabilizando a reprodução do capital enquanto relação social - pautado não pela lógica imediata da concorrência dos capitais individuais, mas por uma visão de conjunto e de longo prazo (Offe, 1975; 1984; Offe \& Ronge, 1984). Essa racionalidade estatal se deve a um fator objetivo e estrutural: para se autorreproduzir, o Estado precisa que a economia capitalista prospere. Uma vez que, na sociedade capitalista, o Estado não dispõe do controle dos meios de produção (Offe \& Ronge, 1984: 123; Marques, 1997: 73), o que significa que ele não é o principal responsável pela organização do processo produtivo, tanto os governantes quanto os funcionários do quadro 
permanente (burocracia) "sabem que precisam introjetar os interesses do capital para manter o financiamento do Estado e, portanto, a possibilidade de exercício do poder" (Miguel, 2018: 49). Para Claus Offe e Volker Ronge,

[...] como o poder estatal depende do processo de acumulação capitalista, sem ser ele mesmo capaz de organizar esse processo, o interesse supremo e mais geral dos detentores do poder do Estado consiste em manter as condições de exteriorização de seu poder através da constituição de condições políticas que favoreçam o processo privado de acumulação. [...] essa conexão entre as condições do exercício do poder estatal e a acumulação privada [...] não se baseia, de modo algum, nem em quaisquer alianças entre o aparelho estatal e certas classes ou camadas, nem ao acesso privilegiado dos membros capitalistas aos centros de decisão do Estado. Este acesso privilegiado, quando ocorre, não é causa, mas sim o reflexo institucional da dependência estrutural da atividade em relação da atividade em relação ao funcionamento da acumulação. [...] os agentes do poder estatal [...] obedecem, como seu mandamento mais alto ao imperativo da constituição e consolidação de um "desenvolvimento econômico favorável" (Offe e Ronge, 1984: 124).

A forma como a sociedade capitalista está estruturada implica, portanto, em uma dependência estrutural do Estado para com o capital, ou seja, a própria sobrevivência material do Estado depende da arrecadação de tributos e, consequentemente, de um determinado nível de atividade econômica (Miguel, 2018: 49). Esse quadro configura um cenário no qual os interesses do sistema estatal encontram correspondência com os interesses do processo de acumulação capitalista, o que significa que o Estado age protegendo os interesses capitalistas não por ser controlado pela burguesia, mas sim em função de seu próprio interesse, um modus operandi que acaba por Ihe conferir uma natureza de classe (Offe, 1984). Em suma, o Estado encontra-se profundamente vinculado aos requisitos funcionais do processo de acumulação do capital (Borchet \& Lessenich, 2016: 23), fator que aumenta as chances de sucesso dos capitalistas no embate político contra outros grupos sociais (Marques, 2016: 23).

É conveniente destacar, contudo, que essa ideia já aparecia na discussão travada por Marx em seu clássico O 18 de Brumário de Luis Bonaparte (publicado originalmente em 1852). Ao analisar os conflitos de interesses entre os camponeses e o Estado bonapartista na França de 1851, Marx afirma que a pequena propriedade rural é sobrecarregada pelos impostos, que se constituem "[n]a fonte de vida da burocracia, do exército, dos padres e da corte, em suma, de toda a máquina do Poder Executivo" (Marx 2006: 137). O que Offe fez, na realidade, foi desenvolver a fundo essa discussão, produzindo efetivamente um modelo teórico com grande poder explicativo sobre a dinâmica da ação estatal na sociedade capitalista. 
O fato é que, na medida em que o nível da atividade econômica - e, portanto, da arrecadação tributária - depende fundamentalmente das decisões dos investidores privados na economia nacional, o Estado precisa garantir as condições materiais de reprodução do capitalismo tendo em vista sua própria reprodução (Hirsch, 2005: 169). Daí a relevância do conceito de seletividade das instituições políticas, um dos mais importantes na interpretação de Offe sobre o Estado. Segundo a análise do autor, "o sistema de instituições políticas possui uma seletividade própria, especificamente classista, correspondente aos interesses do processo de valorização" (Offe, 1984: 147, grifo no original). Seletividade no sentido trabalhado por Offe significa a instituição de regras de exclusão, ou seja, existe uma institucionalização de certo padrões decisórios em relação a quais interesses serão atendidos e quais sofrerão veto (Marques, 1997: 74). Logo, a proposição de Offe sugere que os mecanismos protetores do interesse capitalista se encontram institucionalizados, ou seja, cristalizados no quadro burocrático permanente do Estado, o que assegura a continuidade desse curso de ação (Borchet \& Lessenich, 2016: 32) independente do grupo político-partidário à frente do governo.

O ponto central é que as estruturas institucionais precisam operar seletivamente em um duplo sentido. Primeiro, considerando que os capitais individuais, em função da própria dinâmica competitiva na qual estão inseridos, não são capazes de atuar coletivamente no sentido de forjar um interesse "global" e de longo prazo da classe capitalista em seu conjunto, é necessário que as estruturas institucionais do Estado trabalhem nessa direção. Em outras palavras, essa seletividade institucional precisa proteger a classe dominante dela mesma, isto é, de seus interesses contraditórios e imediatistas, atuando de modo a decantar um "interesse de classe", aquilo que Offe (1984: 149) denomina por "interesses globais do capital". A clássica formulação do Manifesto Comunista de 1848 - o Estado moderno como um comitê para gerenciar os negócios comuns de toda a burguesia - já apontava precisamente nessa direção. O primeiro elemento da seletividade institucional, portanto, funciona justamente no sentido de que o Estado atua como representante geral da classe capitalista, articulando e integrando seus interesses em uma perspectiva mais ampla e de longo prazo.

O segundo sentido da seletividade das instituições estatais refere-se precisamente à imposição autoritária de um interesse de classe, ou seja, à necessidade de impor um veto e de funcionar como filtro dos interesses e projetos emergentes no plano social que eventualmente representem ameaças reais ao interesse capitalista global. É a ação do Estado contra qualquer tipo de "consciência anticapitalista". Nesse sentido, a dominação estatal só adquire verdadeiramente um sentido de classe quando se forja nesse duplo sentido apontado por Offe (1984: 150). 
É importante ponderar, contudo, que o Estado não é uma entidade com "poder divino" capaz de antecipar completamente todas as supostas ou potenciais ameaças aos interesses dos grandes capitalistas. A realidade é profundamente complexa e atravessada por conflitos sociais que rebatem no Estado, o que provoca diversos choques no processo de formulação, de tomada de decisão e de implementação das políticas estatais (Marques, 2013; Howlett, Ramesh \& Perl, 2013). Como nos recordam Perissinotto e Codato (2010: 44), não pode ser descartada a possibilidade de que as ações estatais produzam "efeitos disfuncionais não antecipados para a reprodução da ordem social". Ainda segundo os autores, é o próprio Offe quem estabelece que

o caráter de classe do Estado é algo que se detecta apenas post festum, isto é, apenas pela análise dos efeitos concretos que as decisões estatais produzem sobre o sistema social (Perissinotto \& Codato, 2010: 41).

Isso requer a realização de análises empíricas para avaliar cada caso específico, o que significa que a intencionalidade das políticas estatais e os seus efeitos nunca podem ser total e adequadamente avaliados de imediato.

Por sua vez, a análise de Nicos Poulantzas, o primeiro autor a colocar o Estado no centro do debate marxista (Marques, 1997: 70), também oferece contribuições fundamentais para a interpretação do Estado na sociedade capitalista. A obra desse pensador é habitualmente dividida em duas fases principais: a primeira fortemente marcada pela influência estruturalista de Louis Althusser, na qual o Estado é definido por suas funções (Poulantzas, 1986), e a segunda, caracterizada por uma abordagem que coloca em primeiro plano as relações que constituem o Estado (Poulantzas 1981), na qual o debate se centra não mais em suas funções, mas em sua natureza (Marques, 1997: 71; 2016: 21-22). Para os fins deste artigo, interessa-nos discutir elementos inerentes ao segundo momento. Em sua obra O Estado, o poder, o socialismo, originalmente publicada em 1978, Poulantzas se coloca a tarefa de "compreender a inscrição da luta de classes, muito particularmente da luta e da dominação política, na ossatura institucional do Estado [...]" (Poulantzas, 1981: 144, grifo no original). Em abordagem fortemente inspirada nos escritos de Antonio Gramsci sobre hegemonia (Carnoy, 1994), o autor compreende o Estado a partir da "natureza" de suas relações, definindo-o como "a condensação material e específica de uma relação de forças entre classes e frações de classe" (Poulantzas, 1981: 148, grifo no original), o que significa, acima de tudo, conceber o Estado como arena da luta de classes, palco no qual os atores, vinculados aos diferentes interesses existentes na sociedade, travam conflitos e disputam posições hegemônicas, buscando sempre direcionar a atuação do Estado e de seus diferentes subaparelhos (Brand \& Heigl, 2011). 
Nesse sentido, o Estado não é, e nem poderia ser, um órgão "exclusivo" de uma classe; as classes dominadas se fazem presentes no aparelho de Estado e disputam contra as classes dominantes posições dentro dessa arena mais ampla. Ao afirmar que o Estado não é um bloco monolítico, mas "um campo e um processo estratégicos" (Poulantzas, 1981: 157, grifo no original), Poulantzas se embasa no conceito gramsciano de hegemonia "em toda a sua complexidade [...] e o articula para o Estado" (Carnoy, 1994: 160), assumindo que os conflitos - pela hegemonia - no interior do Estado ocorrem tanto entre os seus aparelhos como também no interior de cada um deles. Desse modo, Poulantzas rechaça em definitivo a ideia de que as classes dominadas atuam apenas "do lado de fora do Estado", circundando-o e assediando-o como se fosse uma fortaleza impenetrável para estes grupos. Com efeito, prossegue o teórico marxista,

as lutas populares atravessam o Estado de lado a lado, [isto é, tais lutas] estão desde já inscritas na trama do Estado do qual elas esboçam a configuração estratégica (Poulantzas, 1981: 162).

É visível, portanto, que muito do que foi discutido pelos estudiosos brasileiros sobre a interação entre movimentos sociais e Estado, na perspectiva da agenda relacional, guarda forte semelhança com as noções poulantzianas sobre o Estado e o conflito social. Embora, na essência, o debate brasileiro nos últimos anos tenha passado longe de categorias marxistas fundamentais - como "Estado capitalista", "burguesia" e "classes sociais" -, os pesquisadores envolvidos com a chamada agenda relacional ofereceram uma interpretação amplamente calcada na ideia de que os movimentos sociais e outros atores oriundos da sociedade civil passaram a disputar posições no Estado - e, portanto, passaram a disputar o próprio Estado em suas diferentes arenas, travando uma verdadeira batalha pela hegemonia em seu interior. Essa disputa teria se "iniciado" de forma mais incisiva desde a redemocratização do país, mas tornou-se muito mais intensa, por razões óbvias, com vitória de Lula da Silva para o governo federal em 2002. O trânsito de ativistas rumo à ocupação de cargos na burocracia e a inserção de vários militantes em espaços participativos seriam a representação essencial dessa disputa por dentro das instituições estatais (Feltran, 2006; Serafim, 2013; Abers, Serafim \& Tatagiba, 2014).

Todavia, o ponto crucial para Poulantzas - e para o nosso argumento -, é que a presença das classes dominadas no Estado não significa que elas tenham condições de disputar sua hegemonia em condições de igualdade com os grupos dominantes:

[...] a existência das classes populares não se materializa no seio do Estado da mesma maneira que as classes e frações dominantes, mas de maneira específica. [...] Esse arcabouço [do Estado] consis- 
te em mecanismos internos de reprodução da relação dominação-subordinação: ela assegura a presença de classes dominadas em seu seio, embora exatamente como classes dominadas. Mesmo no caso de uma mudança da relação de forças e da modificação do poder de Estado em favor das classes populares, o Estado tende, a curto ou longo prazo, a restabelecer sob nova forma algumas vezes, a relação de forças em favor da burguesia. E o remédio para isso não seria [...] a "tomada" dos aparelhos de Estado pelas massas populares, como se fosse o caso de penetrar em alguma coisa afinal que seria até então externa a elas e de fazer com que tudo mudasse apenas pela virtude de sua súbita presença no interior da fortaleza. As classes populares sempre estiveram presentes no Estado, sem que isso tenha modificado jamais alguma coisa no núcleo essencial desse Estado. A ação das massas populares no seio do Estado é a condição necessária para sua transformação, mas não suficiente (Poulantzas, 1981: 164-165, grifo no original).

Ao reforçarem essa análise, Ulrich Brand e Miriam Heigl afirmam que na discussão de Poulantzas o Estado constitui um "terreno estratégico dotado de uma seletividade estrutural", o que explica porque "as diferentes forças sociais têm diferentes graus de acesso a ele" (Brand \& Heigl, 2011: 248, tradução livre). Isto quer dizer que, mesmo presentes na ampla estrutura institucional do Estado, as classes populares não são capazes de afetar o seu "núcleo essencial", ou seja, aqueles subaparelhos efetivamente dotados de poder real (Poulantzas, 1981: 158).

O caso do Ministério das Cidades, estudado por Serafim (2013), é bastante emblemático dessa dinâmica ${ }^{6}$. Criado em 2003 pelo Governo Lula, foi considerado uma conquista histórica de grande relevância pelos movimentos ligados à luta pela reforma urbana e pelo direito à cidade no Brasil, institucionalizando diversas demandas colocadas por estes atores ao longo de décadas de mobilização. Responsável por articular e implementar uma política nacional de desenvolvimento urbano, o Ministério das Cidades enfrentou, desde o início, o desafio de deter atribuições formais que demandavam grande autonomia decisória e, especialmente, financeira, e ainda de estar ao mesmo tempo efetivamente subordinado ao que Serafim chamou de "Núcleo Estratégico" do governo, tendo que "disputar poder decisório sobre ações que se concentravam nesse Núcleo" (Serafim, 2013: 127) - constituído, segundo a autora, pela Casa Civil e pelos Ministério da Fazenda e do Planejamento.

Estes órgãos impunham constantemente vetos e restrições tanto no que se refere à disponibilidade orçamentária como também aos projetos participativos ${ }^{7}$ elaborados no âmbito do Ministério das Cidades (Serafim, 2013: 140), evidenciando que este apresentava um "baixo poder" perante o Núcleo Estratégico (Serafim, 2013: 183). Ao se embasar na análise de Poulantzas (1981: 158-161), isso significa que
6. Muito embora a autora não tenha se utilizado do referencial poulantziano, sua análise nos permite o estabelecimento dessas conexões entre o caso empírico analisado e a teorização de Poulantzas sobre o Estado.

7. Conforme demonstrado por Serafim (2013), a principal finalidade dos projetos participativos elaborados no momento da criação do Ministério das Cidades consistia em partilhar poder decisório com os atores civis em relação aos rumos da política urbana, uma vez que os grupos à frente do ministério guardavam forte afinidade com o ideário democráticoparticipativo. Com a mudança no comando da pasta, em 2005, esse projeto vai sendo cada vez mais enfraquecido, muito embora a participação civil tenha continuado formalmente até 2017, ano em que o Conselho Nacional das Cidades deixou de funcionar. 
o Ministério das Cidades dispunha de um poder formal que não era capaz de se transformar em poder real no contexto das disputas travadas pelos diferentes subaparelhos no interior do Estado.

Diante das perspectivas teóricas apresentadas neste tópico, como pensar, então, a relação entre os movimentos sociais e o Estado?

\section{Crítica à agenda relacional: para repensarmos a relação entre movimentos sociais e sistema estatal}

De que forma as análises aqui expostas contribuem, portanto, para o atual debate em curso sobre movimentos sociais e Estado no Brasil? Um dos pontos em que vários autores de peso no debate teórico nacional têm insistido é que as transformações no Estado brasileiro desde sua redemocratização nos impedem de corroborar algumas concepções tradicionais em relação aos movimentos sociais e às suas formas de ação. Nesse sentido, a profunda imbricação entre os atores do mundo societal e da esfera político-institucional nos desautoriza a conceber os movimentos sociais como puros e simples outsiders, posicionados externamente em relação ao Estado e que estruturam sua relação com as instituições políticas apenas pela via do enfrentamento direto.

De fato, a "tradicional" imagem dos movimentos como outsiders e, portanto, como atores desafiantes que não gozam de nenhum acesso à polity, parece não encontrar respaldo na realidade. Os ativistas sociais estabelecem relações complexas e multifacetadas com as agências estatais, combinando protesto e inserção institucional em sua interação com o ambiente político. Todavia, isso nos autoriza a conceber os movimentos sociais na chave inversa, isto é, como insiders? Quando eles passam a ter algum acesso ao Estado, deixam de ser atores eminentemente desafiantes para atuar de forma predominantemente colaborativa com as autoridades? A problematização proposta por este artigo recomenda maiores cuidados antes de retirar dos movimentos sociais o status de outsiders, uma vez que o acesso que eles têm não se converte necessariamente em capacidade de direcionar a ação estatal conforme seus objetivos mais amplos e de longo prazo. É certo, portanto, que a imagem clássica dos movimentos como atores externos às instituições não corresponde à realidade, mas retirar a condição de outsiders destes atores significa pressupor uma capacidade de influência que eles seguramente não têm.

As contribuições teóricas de Offe e Poulantzas sobre o Estado nos recomendam adotar uma postura muito mais cautelosa no que tange às possibilidades de trans- 
formação política pela via da ação institucional. No caso brasileiro, especificamente, o profundo otimismo com que muitos pesquisadores interpretaram a chegada do PT à Presidência da República, em 2003, colaborou para que questões estruturais relacionadas ao funcionamento e à dinâmica do Estado fossem desconsideradas no debate teórico, apostando com demasiada expectativa em uma transformação social efetiva a partir do Estado. No Estado capitalista, portanto, é claro que a vitória eleitoral de um partido de esquerda pode representar avanços importantes em alguns pontos, tanto no que se refere à inclusão de novos atores nas diferentes ramificações do aparelho estatal, como ainda em relação à formulação e implementação de políticas públicas mais voltadas às classes populares. Mas os limites desse avanço por dentro das instituições sempre estiveram muito evidentes.

A rigor, estar dentro do Estado não significa deter o controle do poder estatal. A ascensão de um partido como o PT à Presidência pode acarretar - como realmente acarretou - mudanças importantes na própria configuração institucional do Estado, como a criação de espaços participativos e na produção de políticas públicas mais inclusivas e democráticas, mas não elimina a lógica de funcionamento de suas estruturas fundamentais. O Estado é algo muito maior e mais complexo do que o governo em exercício e seus quadros comissionados, o que reduz a possibilidade de transformação dessa engrenagem desde dentro. O caso brasileiro é apenas mais um a demonstrar que as possibilidades de uma efetiva transformação social são bastante reduzidas quando a luta por dentro do Estado assume tamanha centralidade. Nas palavras de Luís Felipe Miguel, a mobilização social pode até ser direcionada para dentro do aparelho estatal, mas

não há transformação possível sem investimento na luta extrainstitucional [ou seja] a pressão pela mudança [...] só tem condições de triunfar se estiver fortemente ancorada do lado de fora (Miguel, 2017: 62).

É importante salientar que a posição assumida neste artigo não significa que sejamos contrários a uma abordagem relacional para a análise das relações entre movimentos sociais e Estado. O debate brasileiro conseguiu avançar suficientemente para compreendermos que não há como negar os vínculos que entrelaçam os movimentos sociais ao sistema estatal. Nossa objeção é com a ênfase desmedida que vários pesquisadores do cenário nacional atribuíram à luta por dentro do Estado sem problematizar certos elementos que são centrais para a compreensão desse conjunto de instituições. A literatura que se propôs a romper com as formulações dicotômicas do passado trabalhou explicitamente com a premissa de que o Estado está em disputa. De fato, ele está, mas essa disputa se dá em termos profundamente desfavoráveis para os movimentos populares que lutam por avanços democráticos. 
Com isso, não estamos afirmando que os partidários da agenda relacional simplesmente ignoraram as assimetrias inerentes à disputa política na arena estatal. Abers e von Bülow, por exemplo, apresentam uma breve ressalva na conclusão de seu texto citado neste artigo, apontando que os indivíduos quando ingressam no Estado se inserem em uma hierarquia que restringe sua autonomia de ação "e que submete suas ações ao poder de veto de atores com uma lógica distinta", o que se aplica também aos militantes de movimentos sociais, que, inseridos nessa complexa teia relacional que é o Estado, podem passar "a defender posições mais moderadas ou até contrárias à missão do movimento" (Abers \& von Bülow, 2011: 78). Marcelo Silva e Gerson Oliveira, por sua vez, inserem uma nota de rodapé para explicar que há variações nas oportunidades de acesso aos diferentes setores do Estado/governo:

Enquanto alguns setores do governo Lula eram considerados altamente permeáveis por certas organizações de movimentos sociais, outros eram avaliados como totalmente impermeáveis e, logo, adversários (Silva \& Oliveira, 2011: 98, nota de rodapé).

As duas citações nos remetem respectivamente às análises de Offe e Poulantzas, constituindo temas e problemas centrais no debate sobre o Estado. Mas, como se nota a partir de uma análise cuidadosa da literatura nacional referente ao tema, são justamente esses pontos mais relevantes que estão relegados a segundo plano, ou seja, não estiveram centralmente presentes nas preocupações desses pesquisadores. Travar o debate que a agenda relacional se propôs sem problematizar teoricamente o que é o Estado na sociedade capitalista, quais suas lógicas e dinâmicas de funcionamento e, portanto, quais as possibilidades de uma transformação mais incisiva das relações sociais a partir de uma ação política que tenha o Estado como foco, implica o risco de produzirmos análises insuficientes para uma compreensão mais realista da luta pela democracia em nossa sociedade.

\section{Considerações finais}

Este texto teve como objetivo fundamental discutir a relação entre movimentos sociais e sistema estatal pela ótica neomarxista, embasando-se, fundamentalmente, nas contribuições de Nicos Poulantzas e Claus Offe. No primeiro tópico, apresentamos as linhas gerais do atual debate sobre a interação entre movimentos sociais e Estado no Brasil contemporâneo, fortemente influenciado pelo que denominamos aqui por uma abordagem relacional nesse campo de estudos, cuja finalidade central consiste em jogar luz nas inúmeras formas de interação institucional estabelecidas entre ativistas e atores estatais. Como foi demonstrado, essa linha de análise se consolidou nos últimos anos como um esforço em contrapor as concepções di- 
cotômicas que haviam pautado o debate teórico sobre a mobilização social e a luta pela democracia nas décadas anteriores. Apontamos, todavia, que o problema é que esse esforço foi realizado sem uma teorização adequada sobre o Estado e sua dinâmica de funcionamento.

Em seguida, no segundo tópico do texto, trouxemos as discussões sobre o Estado enquanto condensação material de uma relação de forças e a seletividade das instituições políticas, travadas respectivamente por Poulantzas e Offe. No primeiro caso, trata-se de compreender o Estado como um campo de batalha estratégico, no qual as classes populares se fazem presentes e travam uma disputa hegemônica em seu interior, uma disputa, todavia, que não se dá em condições de igualdade em relação às classes hegemônicas. Já no caso de Offe, a ideia central gira em torno da ideia da dependência estrutural do Estado para com o capital, o que obriga os agentes estatais a internalizarem os interesses da classe dominante no que tange à reprodução ampliada do capital. Neste quadro, as instituições estatais agem pautadas por uma seletividade política com o objetivo de proteger os interesses de longo prazo dos grandes capitalistas, viabilizando a reprodução da sociedade capitalista para que, dessa forma, o próprio Estado possa continuar existindo.

A terceira seção procurou realizar um contraponto entre as contribuições teóricas dos dois autores neomarxistas analisados no texto e os pressupostos da agenda relacional. Como foi explicado, essa agenda teve muitos méritos em questionar e refutar as concepções dicotômicas e maniqueístas que embasaram a análise sobre a relação entre movimentos sociais e Estado no Brasil, ao longo de vários anos. Ao fazer isso, a agenda relacional também foi capaz de demonstrar a insuficiência das escolas teóricas mais consolidadas sobre movimentos sociais para a explicação da realidade brasileira. Sem negar esses vários ganhos analíticos, a problematização que trouxemos foi no sentido de demonstrar que esse debate prescindiu de uma análise teórica mais aprofundada sobre o Estado na sociedade capitalista, e, consequentemente, que a dinâmica de funcionamento do aparelho estatal limita as possibilidades de uma transformação social mais efetiva a partir de uma mobilização que tenha como foco esse mesmo Estado.

Como já destacamos na Introdução do artigo, sabemos que a análise neomarxista também tem suas limitações em termos teóricos, e que ela, por si só, não é suficiente para explicar a relação entre Estado e sociedade. Todavia, o campo de estudos sobre movimentos sociais e participação no Brasil tem muito a ganhar em termos analíticos com a incorporação das questões centrais sobre o Estado trazidas por essa perspectiva. É fato que a agenda relacional trouxe um debate muito 
qualificado sobre o tema que se propôs enfrentar, mas, ao mesmo tempo, esse campo de estudos manteve, com raras exceções, uma postura muito refratária em relação às abordagens mais alinhadas com o marxismo, incluindo o debate sobre o Estado. Afinal, ainda que isso nem sempre tenha sido explicitado pelos partidários da agenda relacional, de um modo geral os pressupostos teóricos que hegemonizaram o debate proposto por esta agenda estão profundamente alinhados com as perspectivas neoinstitucionalistas, escola de pensamento adversária do marxismo (Marques, 1997; Rocha, 2005).

Entretanto, acreditamos que o retrocesso democrático em marcha na sociedade brasileira - processo que implicou em profundo realinhamento de forças no âmbito do Estado -, dificilmente pode ser explicado sem uma ampliação do diálogo teórico com outras vertentes. O neomarxismo é apenas uma possibilidade a ser explorada nessa direção. Nosso esforço neste texto foi apresentar um caminho inicial para a construção de uma agenda de pesquisa capaz de incorporar criticamente o debate sobre o Estado, com o intuito de produzir uma análise mais realista sobre os limites da luta pela via institucional, mas evitando, ao mesmo tempo, cair nas armadilhas de uma leitura dicotômica e maniqueísta.

\section{Referências}

ABERS, Rebecca; von BÜLOW, Marisa. Movimentos sociais na teoria e na prática: como estudar o ativismo através da fronteira entre Estado e sociedade? Sociologias, n. 28, p. 52-84, 2011.

ABERS, Rebecca; SERAFIM, Lizandra; TATAGIBA, Luciana. Repertórios de interação Estado-Sociedade em um Estado heterogêneo: a experiência na era Lula. Dados, v. 57, n. 2, p. 325-357, 2014.

ALMEIDA, Carla; TATAGIBA, Luciana. Os conselhos gestores sob o crivo da política: balanços e perspectivas. Serviço Social \& Sociedade, n. 109, p. 68-92, 2012.

ALMEIDA, Debora Cristina Rezende de. Os desafios da efetividade e o estatuto jurídico da participação: a Política Nacional de Participação Social. Sociedade e Estado, v. 32, n. 3, p. 649-679, 2017.

ALONSO, Angela. As teorias dos movimentos sociais: um balanço do debate. Lua Nova, n. 76, p. 49-86, 2009.

AVRITZER, Leonardo. Impasses da democracia no Brasil. Rio de Janeiro: Civilização Brasileira, 2016. 
— Instituições participativas e desenho institucional: algumas considerações sobre a variação da participação no Brasil democrático. Opinião Pública, v. 14, n. 1, p. 43-64, 2008.

BAVA, Silvio Caccia. A luta nos bairros e a luta sindical. In: L. KOWARICK (Org.). As lutas sociais e a cidade. São Paulo: Paz e Terra, 1994.

BLIKSTAD, Karin. O agir coletivo nas interfaces da sociedade civil e do sistema estatal: o caso da atuação do movimento de moradia de São Paulo sobre a política pública de habitação. Dissertação (Mestrado em Ciência Política) - Instituto de Filosofia e Ciências Humanas, Universidade Estadual de Campinas, Campinas, 2012.

BORCHET, Jens; LESSENICH, Stephan. Claus Offe and the critical theory of the Capitalist State. New York: Routledge, 2016.

BRAND, Ulrich; HEIGL, Miriam. "Inside" and "outside": the State, movements and "radical transformation" in the work of Nicos Poulantzas. In: A. GALLAS; L. BRETTHAUER; J. KANNANKULAM; I. STÜTZLE (Orgs.). Reading Poulantzas. Pontypool (CA): Merlin Press, 2011.

BUECHLER, Steven M. Understanding social movements: theories from the classical era to the present. New York: Routledge, 2016.

CALDEIRA, Teresa; HOLSTON, James. Estado e espaço urbano no Brasil: do planejamento modernista às intervenções democráticas. In: AVRITZER, L. (Org.). A participação em São Paulo. São Paulo: Editora Unesp, 2004.

CARDOSO, Ruth Correia Leite. A trajetória dos movimentos sociais. In: DAGNINO, E. (Org.). Os anos 90: política e sociedade no Brasil. São Paulo: Brasiliense, 1994.

CARLOS, Euzeneia. Movimentos sociais e instituições participativas: efeitos do engajamento institucional nos padrões de ação coletiva. Revista Brasileira de Ciências Sociais, v. 30, n. 88, p. 83-99, 2015.

- Mudanças e continuidades no movimento de direitos humanos: padrões organizacionais, relacionais e discursivos. Opinião Pública, v. 20, n. 3, p. 450-479, 2014.

CARNOY, Martin. Estado e teoria política. Campinas (SP): Papirus, 1994.

DAGNINO, Evelina. Sociedade civil e espaços públicos no Brasil. In: DAGNINO, Evelina (Org.). Sociedade civil e espaços públicos no Brasil. São Paulo: Paz e Terra, 2002. 
DAGNINO, Evelina; OLVERA, Alberto; PANFICHI, Aldo (Orgs.). A disputa pela construção democrática na América Latina. São Paulo: Paz e Terra, 2006.

DOIMO, Ana Maria. A vez e a voz do popular: movimentos sociais e participação política no Brasil pós-70. Rio de Janeiro: Relume-Dumará, 1995.

FELTRAN, Gabriel. Vinte anos depois: a construção democrática brasileira vista da periferia de São Paulo. Lua Nova, n. 72, p. 83-114, 2007.

- Deslocamentos - trajetórias individuais, relações entre sociedade civil e Estado no Brasil. In: DAGNINO, E.; OLVERA, A.; PANFICHI, A. (Orgs.). A disputa pela construção democrática na América Latina. São Paulo: Paz e Terra, 2006.

- Desvelar a política na periferia: histórias de movimentos sociais em São Paulo. São Paulo: Humanitas/Fapesp, 2005.

GOHN, Maria da Glória. Teorias dos movimentos sociais: paradigmas clássicos e contemporâneos. São Paulo: Edições Loyola, 2010.

GURZA LAVALLE, Adrian. Após a participação: nota introdutória. Lua Nova, n. 84, p. 13-23, 2011.

- Sem pena nem glória: o debate da sociedade civil nos anos 1990. Novos Estudos, v. 66, n. 66, p. 91-110, 2003.

GURZA LAVALLE, Adrian; ISUNZA VERA, Ernesto. A trama da crítica democrática: da participação à representação e à accountability. Lua Nova, n. 84, p. 95-139, 2011.

GURZA LAVALLE, Adrian; SZWAKO, José. Sociedade civil, Estado e autonomia: argumentos, contra-argumentos e avanços no debate. Opinião Pública, v. 21, n. 1, p. 157-187, 2015.

HIRSCH, Joaquim. ¿Qué significa Estado? Reflexione acerca de la teoría del Estado capitalista. Rev. Sociol. Polít., n. 24, p. 165-175, 2005.

HOWLETT, Michael; RAMESH, Michael; PERL, Anthony. Política pública: seus ciclos e subsistemas. Rio de Janeiro: Elsevier Editora, 2013.

JACOBI, Pedro. Movimentos sociais urbanos no Brasil: reflexão sobre a literatura nos anos 70 e 80. Revista Brasileira de Informação Bibliográfica em Ciências Sociais (BIB), n. 23, p. 18-34, 1987.

JASPER, James M. Protesto: uma introdução aos movimentos sociais. Rio de Janeiro: Zahar, 2016. 
KOWARICK, Lúcio. Movimentos urbanos no Brasil contemporâneo: uma análise da literatura. Revista Brasileira de Ciências Sociais, v. 1, n. 3, p. 38-50, 1987.

MARICATO, Erminia. O impasse da política urbana no Brasil. Petrópolis (RJ): Vozes, 2014.

MARQUES, Eduardo. De volta aos capitais para melhor entender as políticas urbanas. Novos Estudos, v. 35, n. 2, p. 14-33, 2016.

As políticas públicas na ciência política. In: MARQUES, E.; FARIA, C. A. P. de (Orgs.). A política pública como campo multidisciplinar. São Paulo; Rio de Janeiro: Editora Unesp; Editora Fiocruz, 2013.

- Notas críticas a literatura sobre Estado, políticas estatais e atores políticos. Revista Brasileira de Informação Bibliográfica em Ciências Sociais (BIB), v. 43, p. 67-102, 1997.

MARX, Karl. O 18 de Brumário de Luís Bonaparte. São Paulo: Centauro, 2006 [1852].

MIGUEL, Luís Felipe. Dominação e resistência: desafios para uma política emancipatória. São Paulo: Boitempo, 2018.

- Democracia fraturada: o golpe, os limites do arranjo concorrencial e a perplexidade da ciência política. In: MIGUEL, L. F.; BIROLI, F. (Orgs.). Encruzilhadas da democracia. Porto Alegre (RS): Zouk, 2017.

MILIBAND, Ralf. O Estado na sociedade capitalista. Rio de Janeiro: Zahar, 1972.

MISCHE, Ann. Partisan publics: communication and contention across Brazilian youth activist networks. Princeton (NJ): Princeton University Press, 2008.

OFFE, Claus. Dominação de classe e Sistema estatal. Sobre a seletividade das instituições políticas". In: OFFE, C. (Org.). Problemas estruturais do Estado capitalista. Rio de Janeiro: Tempo Brasileiro, 1984.

. The theory of capitalist state and the problem of policy formation. In: LINDBERG, L. et alii (Orgs.). Stress and contradictions in modern capitalism. Washington (DC): Lexington Books, 1975.

OFFE, Claus; RONGE, Volker. Teses sobre a fundamentação do conceito de Estado Capitalista e sobre a pesquisa política de orientação materialista. In: OFFE, C. (Org.). Problemas estruturais do Estado capitalista. Rio de Janeiro: Tempo Brasileiro, 1984. 
PAOLI, Maria Célia. Movimentos sociais no Brasil: em busca de um estatuto político". In: HELLMANN, M. (Org.). Movimentos sociais e democracia no Brasil. São Paulo: Marco Zero, 1995.

PERISSINOTTO, Renato; CODATO, Adriano. Marx e seu legado para a teoria contemporânea do Estado capitalista. Revista Brasileira de Informação Bibliográfica em Ciências Sociais (BIB), n. 70, p. 31-50, 2010.

PIRES, Roberto Rocha Coelho. Da sociedade para o Estado: desafios da participação no Brasil. In: MARX, V. (Org.). Democracia participativa, sociedade civil e território. Porto Alegre (RS): Edutora UFRGS; Cegov, 2014.

POULANTZAS, Nicos. Poder político e classes sociais. São Paulo: Martins Fontes, 1986 [1968].

O Estado, o poder, o socialismo. São Paulo: Paz e Terra, 1981 [1978].

ROCHA, Carlos Vasconcelos. Neoinstitucionalismo como modelo de análise para as políticas públicas: algumas observações. Civitas, v. 5, n. 1, p. 11-28, 2005.

ROMÃO, Wagner de Melo. Reflexões sobre as dificuldades da implementação da participação institucional no Brasil. Ideias, v. 6, n. 2, p. 35-38, 2015.

SADER, Eder. Quando novos personagens entram em cena-experiências, falas e lutas dos trabalhadores da Grande São Paulo (1970-80). São Paulo: Paz e Terra, 1988.

SERAFIM, Lizandra. Participação no governo Lula: as pautas da reforma urbana no Ministério das Cidades (2003-2010). Tese (Doutorado em Ciências Sociais) - Instituto de Filosofia e Ciências Humanas, Universidade Estadual de Campinas, Campinas, São Paulo, 2013.

SILVA, Carla Almeida. Os fóruns temáticos da sociedade civil: um estudo sobre o Fórum Nacional de Reforma Urbana. In: DAGNINO, E. (Org.). Sociedade civil e espaços públicos no Brasil. São Paulo: Paz e Terra, 2002.

SILVA, Marcelo Kunrath. Movimentos sociais no Brasil: institucionalização e contestação. Trabalho apresentado no III Congreso Latinoamericano y Caribeño de Ciencias Sociales. Quito (EC): Flacso, 2015.

Sociedade civil e construção democrática: do maniqueísmo essencialista à abordagem relacional. Sociologias, n. 16, p. 156-179, 2006. 
SILVA, Marcelo Kunrath; OLIVEIRA, Gerson de Lima. A face oculta(da) dos movimentos sociais: trânsito institucional e intersecção Estado-Movimento - uma análise do Movimento de Economia Solidária no Rio Grande do Sul. Sociologias, n. 28, p. 86-124, 2011.

SWZAKO, José. Participar vale a pena, mas...: a democracia participativa brasileira vista pelas lentes da utopia. In: SOUTO, A. L. S.; PAZ, R. D. O. da (Orgs.). Novas lentes sobre a participação: utopias, agendas e desafios. São Paulo: Instituto Pólis, 2012.

TARROW, Sidney. Power in movement: social movements and contentious politics. Cambridge (UK): Cambridge University Press, 2011.

TATAGIBA, Luciana. Relação entre movimentos sociais e instituições políticas na cidade de São Paulo: o caso do movimento de moradia. In: KOWARICK, L.; MARQUES, E. (Orgs.). São Paulo: novos percursos e atores. São Paulo: Editora 34, 2011.

- Movimentos sociais e sistema político. Um diálogo (preliminar) com a literatura. Trabalho apresentado no VI Encontro da Associação Brasileira de Ciência Política. Campinas (SP): Unicamp, 2008.

. Os conselhos gestores e a democratização das políticas públicas no Brasil. In: DAGNINO, E. (Org.). Sociedade civil e espaços públicos no Brasil. São Paulo: Paz e Terra, 2002.

TATAGIBA, Luciana; TEIXEIRA, Ana Claudia Chaves. Efeitos combinados dos movimentos de moradia sobre os programas habitacionais autogestionários. Rev. Sociol. Polít., v. 24, n. 58, p. 85-102, 2016.

TAVARES, Francisco Mata Machado. Austeridade e política democrática no Sul Global: uma abordagem crítica a partir do caso brasileiro. Trabalho apresentado no IX Congreso Latinoamericano de Ciencia Política. Montevideo: Alacip, 2017.

Em busca da deliberação: mecanismos de inserção das vozes subalternas no espaço público. Revista Brasileira de Ciência Política, n. 9, p. 39-70, 2012.

TEIXEIRA, Ana Claudia Chaves. Para além do voto: uma narrativa sobre a democracia participativa no Brasil (1975-2010). Tese (Doutorado em Ciências Sociais) - Instituto de Filosofia e Ciências Humanas, Universidade Estadual de Campinas, Campinas, São Paulo, 2013.

TEIXEIRA, Ana Claudia Chaves; TATAGIBA, Luciana. Democracia participativa em la ciudad de São Paulo: continuidades y rupturas. In: ISUNZA VERA, E. ; GURZA LAVALLE, A. (Orgs.). La innováción democrática em América Latina. México: Ciesas, 2010. 
TELLES, Vera da Silva. Anos 70: experiências, práticas e espaços políticos. In: KOWARICK, L. (Org.). As lutas sociais e a cidade: São Paulo passado e presente. Rio de Janeiro: Paz e Terra, 1988.

TILLY, Charles. Movimentos sociais como política. Revista Brasileira de Ciência Política, n. 3, p. 133-160, 2010.

. Contentious repertoires in Great Britain, 1758-1834". In: TRAUGOTT, M. (Org.). Repertoires and cycles of collective action. Durham (NC): Duke University Press, 1995.

TRINDADE, Thiago Aparecido. Os limites da democracia: a legitimidade do protesto no Brasil participativo. Revista Brasileira de Ciências Sociais, v. 33, n. 97, p. 1-20, 2018.

(c) (i) (9) 